\title{
A FUNÇÃO RENOVADORA DO DIREITO *
}

\author{
Prof. ORLANDO GOMES \\ (Catedrático das Faculdades de Direito e Ciências \\ Econômicas da Universidade da Bahia.)
}

1. O pendor imobilista dos juristas em geral e sua tendência conservadora, traduzem-se num estado de espírito que busca sua justificação filosófica na preferência por uma concepção que atribui ao Direito um papel puramento passivo e acess6rio.

A história do pensamento jurídico assinala-se, entretanto, pela oscilação do seu pêndulo entre tal concepção e a que preconiza e ressalta a função criadora do Direito.

Ao longo de seu fluxo, projeta-se a luta interminável entre a tradição e o progresso; a controvérsia inexaurível entre a estabilidade e a mudança.

Invocando os mais diversos fundamentos, entendem os tradicionalistas, de todos os tempos, que o ordenamento jurídico da sociedade deve cingir-se, a refletir, ou acompanhar, a realidade social subjacente.

No seu juízo e parecer, as instituições jurídicas têm de resignar-se a expressar apenas os sentimentos cristalizados em longa tradição.

Acreditam os progressistas, ao contrário, que a missão do Direito antes consiste em influir e orientar o desenvolvimento social, devendo o jurista ter sensibilidade política para eliminar o fôsso entre a forma jurídica e a realidade social.

2. Em lúcida análise de comportamento do Direito numa sociedade em transformação, recorda FRIEDMAN, na sua abertura, a controvérsia, ilustrando-a através do confronto entre as posições expressivas de SAVIGNY e BENTHAM.

* Conferência pronunciada em Curitiba, a 28 de agôsto de 1969. 
Fara $\circ$ grande romanista, o legislador sòmente deve entrar em ação quando o costume popular, articulado em parte pelos jurisconsultos, se houver desenvolvido plenamente.

Já BENTHAM acreditava na eficácia das leis reformadoras, racionalmente estruturadas, preconizando que, pelo Direito, se devem estimular e promover reformas sociais.

Êsse ponto-de-vista predomina lògicamente nas épocas das crises anunciadoras de grandes transformações.

3. Ora, os tempos presentes assinalam-se por visíveis sinais de um processo revolucionário, que abala os fundamentos da sociedade e corroi os seus valôres tradicionais.

Essa patente revolução, pejada de céleres e desconcertantes contestações, não pode deixar de atingir o Direito, tanto nas soluções que oferece aos problemas da vida individual e social do homem, como na formulação dos conceitos e regras técnicas que se condensam nos institutos jurídicos.

Mas, surpreendentemente, legisladores e juristas, em grande maioria, apegam-se ao ponto-de-vista conservador, só admitindo, e, ainda assim, a controgôsto, retoques superficiais na legislação, que, por sua timidez, alargam o fôsso, em vez de o diminuir.

Cegos para as mudanças sociais e insensíveis às variações no clima da opinião pública, vêem, com injustificado pavor, em cada proposição autenticamente reformadora, o desabamento da ordem qua a rotina consagrou.

4. Taí cegueira é, até certo ponto, um mal congênito. A segurança constitui uma das finalidades cabedais do Direito eis que, pe'as normas jurídicas, se estabelece a ordem, se assegura a estabilidade e se garante a certeza nas relações entre os indivíduos e dêstes com o Estado. É compreensível que o jurista, trabalhando êsse material, se empenhe na intocabilidade da ordem-de-coisas existente, se as suas antenas, condicionadas ao terra-a-terra da profissão, não captam os sinais que se elevam sôbre a estática do ordenamento que manipulam.

5. A segunda causa da atitude quietista tem, atualmente, sabor de paradoxo.

Juristas alérgicos a qualquer mudança prestam, inconscientemente, vassalagem à doutrina de que o Direito é simples epifenônome da realidade econômica, - substrato teórico que os instigaria 
paradoxalmente a rejeitar, na sua totalidade, a ordem jurídica imperante, e pretender substituí-la de fond en comble.

Participam, dêsse modo, do equívoco que proclama a submissão servil da superestrutura da sociedade à sua infraestrutura, chegando porém, a conseqüências opostas às que resultam dessa falácia.

Mas ainda se admita que as idéias, os mitos, as imagens, os conceitos e as normas de conduta de tôda sociedade refletem sua estrutura econômica e passam a integrar sua cultura, tornando-se imprescindíveis à sua preservação, é forçoso reconhecer que tais formações específicas influem na organização da vida social, - ou para ser mais preciso - que exercem, regressivamente, ação sôbre a base que as segregou.

Se é verdade que o homem toma consciência da realidade de suas condições sociais de existência através dessas segregações, têm elas, quando menos, uma autonomia relativa, de vez que, por seu intermédio, percebem, quando menos, a dissonância entre a realidade econômica e a realidade cultural.

Ainda nessa linha de pensamento, o Direito não careceria, para os que a trilham, de fôrça criadora e construtiva, reduzido, embora, a mero instrumento político.

6. A idéia de que os sistemas jurídicos constituem expressão de ideais e realidades políticas também não conduz necessàriamente à tese da passividade do Direito. Bem se sabe que a tendência totalitária do Estado moderno caracterizada, em tôdas as latitudes, pela expansão excessiva e desordenada do contrôle político de tôdas as atividades públicas e privadas pode ser refreiada ou dificultada, onde sobrevive a separação de podêres, pela ação esclarecida dos administradores do Direito, com o emprêgo hábil da técnica jurídica, como têm procedido grandes juízes da Suprema Côrte americana.

7. Conquanto condenável, essa tendência totalitária mais não é do que uma deformação corrigível do alargamento inevitável da esfera de ação do Estado, talvez uma inchação.

Definitiva ou passageira, é, històricamente, uma realidade. 0 jurista não pode desconhecer que determinou, e está a determinar, de par com outros fatôres, sensíveis transformações nas instituições jurídicas que, tradicionalmente, compõem o quadro de Direito Privado: a família, a propriedade e o contrato.

Pôsto continuem ignoradas nos Códigos arcaicos, tais mudanças já desacreditaram, ou distorceram, na sua feição clássica, essas veneráveis instituições. 
8. Descrédito e distorção de que não querem tomar conhecimento os juristas acadêmicos.

Poucos, realmente, perceberam - apenas para exemplificar que a propriedade, como demonstrou irretorquivelmente KARL RENNER, se tornou uma "concha vazia", enquanto sua função real passou a ser exercida por instituições complementares.

Poucos compreenderam que a "institucionalização do contrato" desintegrou seu conceito clássico e que as condenadas limitações da liberdade de contratar têm sua contrapartida na segurança e nas vantagens reais que asseguram.

Poucos, finalmente, se aperceberam que a lei, reproduzindo a imagem da família patriarcal, se acha tão distante da realidade que a estrutura do grupo doméstico e sua articulação se tornaram, na lei, uma paródia de mau gôsto.

Entretanto tão evidentes contrastes e desajustamentos são perceptíveis a ôlho nu para os que têm os olhos abertos para a realidade e a inteligência isenta de preconceitos. Não há necessidade, portanto, de insistir na sua apresentação.

9. Mais interessantes serão algumas reflexões sôbre aspectos da crise do Direito, no que entende com a sua técnica pròpriamente dita, principalmente porque $\circ$ arcaísmo erudito persiste fascinado pela tradição romana, renovada pela ciência alemã há cem anos como se o mundo houvesse parado no século 19.

É preciso perceber e proclamar que, tal como a política legislativa, a dogmática do Direito envelheceu e se desacreditou.

10. Realmente a imagem social da ciência do Direito Privado, como a projetaram os juristas do século passado, está completamente desfigurada.

Os conceitos se substituem antes mesmo de se modificarem as leis. A estrutura dogmática do Direito desagrega-se sob o pêso de intrusões, que não respeitam o isolacionismo a que a submeteram os conceitualistas, dominados por preocupações puristas. Brechas, cada vez mais largas, fendem o sistema lógico, de circuito fechado, a que se reduziram a ciência e a prática do Direito Privado.

Esse tratamento, inspirado na necessidade de segurança da defunta sociedade liberal (LARENZ) favoreceu a liberdade de contratar, o fracionamento da propriedade territorial, a divisão da herança e os negócios creditícios, conforme notou WIEACKER. 
11. A partir do momento em que novas exigências econô. micas, políticas e sociais suscitaram outras diretrizes para a elaboração e aplicação do Direito, passou-se a sentir a necessidade de reformular os conceitos, de renovar o instrumental jurídico, de modificar o próprio método de sua elaboração, de intentar, em suma, uma revisão crítica. O raciocínio jurídico deixou de corresponder às realidades sôbre as quais assentara, decorrendo, dêsse desajustamento, a impressão de decadência dos próprios institutos jurídicos, e até de declínio do Direito.

12. O esvaziamento dos conceitos romanistas não foi imediatamente notado, porque as realidades que os inspiraram permitiam atribuir-lhes expressão que lhes dissimulava as premissas culturais. Os impulsos políticos que exigiam a incorporação ao sistema jurídico de noções que revelassem ostensiva subordinação à realidade subjacente, e, por outro lado, favoreciam o aproveitamento de conceitos que captavam a essência da experiência jurídica, sem deixar perceber a correspondência à função nova que passaram a desempenhar os institutos jurídicos assim definidos e formulados.

13. Com a propriedade, ocorreu essa dissimulação, e êsse aproveitamento realizou-se com pleno êxito. Tôda a estrutura liberal apoiava-se no conceito de direito subjetivo, explicitado na ordem patrimonial, na proteção dispensada ao pleno poder do indivíduo sôbre as coisas submetidas à sua vontade. Não foi difícil aproveitar o conceito romano de propriedade e expressá-lo em têrmos capazes de o restaurar sem modificações radicais, dando a impressão de identidade do objeto definido, quando, verdadeiramente, tinha substrato diverso. A mudança de função social da propriedade não atingiu sua conceituação, apesar da sua desintegração dêsse instituto por efeito do deslocamento dos bens para outras pessoas, típico da revolução democrática, ocorrido em conseqüência da dissolução das antigas unidades de produção e sua substituição pela emprêsa moderna. Não obstante ser a propriedade, em essência, o domínio das coisas, tinha importância fundamental, no antigo regime, a pessoa do proprietário e a qualidade dos bens (KARL RENNER, The institutions of private law and their social functions).

Êsses aspectos sociais da propriedade tornaram-se jurìdicamente irrelevantes. No entanto, influem na sua conceituação e regime legal. Foi possível definí-la como se houvesse perdurado o antigo substrato, porque êsses aspectos sociais, oriundos das transferências econômicas, ainda não haviam revelado agudamente a impropriedade do conceito, exigindo a mudança do estatuto da propriedade. 
Quando, porém, se acentuaram, descortinando a nova função social da propriedade, e passaram, novamente, a ter relevância a pessoa do proprietário e a qualidade dos bens, o próprio conceito de propriedade, abstraído de outras realidades, inferido de condições sociais diversas, tornou-se manifestamente incongruente. Percebeu-se não ser indiferente pertencerem os bens a um empresário ou a um ocioso, não ter a mesma significação social a propriededa de uma fábrica ou de um bem de consumo. Sentiu-se, enfim, a necessidade de reformular a conceituação, de apoiar a noção em outra realidade social, de depreendê-la, em suma, da essência dos novos fatos.

14. Uma rápida incursão no território do direito das obrigações, revela, igualmente, a impropriedade das conceituações sobreviventes à sua transformação.

A grande contribuição da ciência alemã do século XIX foi a elaboração da teoria do negócio jurídico. Com o máximo apuro, foi arquitetada para institucionalizar a liberdade individual na área dos interêsses particulares. A cada indivíduo atribuía-se ampla esfera de autonomia, estimulando-se sua regulação dêsses interêsses mediante o livre acôrdo de suas vontades soberanas. Fêz-se do contrato, o instrumento, por excelência, da vida econômica e, partindo-se do seu conceito, construiu-se tôda uma armadura lógica de noções, tipificações, classificações e ficções, sistematizadas em função da mesma abstração, inferida corretamente da realidade social de então. Assentou-se êsse conceito no dogma da vontade, e no pressuposto de que a liberdade de ação, no campo dos interêsses patrimoniais, era igual para todos.

15. Desaparecidos os pressupostos concretos, falharam as abstrações, ruindo a construção dogmática. A teoria do negócio jurídico teve de ceder a formas rebeldes de relações irredutíveis aos seus fundamentos lógicos. A ética individual do dever e da liberdade em que se apoiava a eficácia dos negócios jurídicos tornou-se impotente para proporcionar a segurança exigida pelo nôvo teor das relações sociais.

O princípio de equivalência das prestações assume novas formas de expressão, o da relatividade dos efeitos do contrato ganha nova dimensão, e o da imutabilidade de sua eficácia encontra, em diversas teorias, o fundamento de sua rejeição. $O$ próprio conceito de responsabilidade se subverte, deixando de ser a culpa, em situações cada vez mais numerosas, o suporte da obrigação de indenizar. 
16. É, porém, no conceito de contrato que se revelam mais vivamente a estreiteza e a contingência temporal dessas abstrações superadas. Ocupou êle a posição central na Teoria Geral do Direito, enfatisada sua relevância doutrinal e prática no contexto da figura sistemática do negócio jurídico. Tratado como a mais importante espécie da categoria geral das declaraçeõs privadas de vontade destinadas a produzir efeitos jurídicos, (WINDSCHEID, Diritto delle Pandete, vol. 1, pág. 264), o contrato abrangia todos os negócios jurídicos bilaterais (WINDSCHEID, ob. cit., pág. 267), e se apresentava como o instrumento idôneo a tôdas as relações entre particulares, fôsse a compra e venda, fôsse o casamento, fôsse o mandato, fôsse a adoção.

A imagem dêsse negócio jurídico chave projetava-se na aproximação de duas pessoas livres, predispostas a compor interêsses divergentes ou contrapostos, mediante acôrdo de vontades, por via do qual predeterminavam, após negociações preliminares, o conteúdo da relação jurídica que assim criavam, autolimitando, cada qual, sua liberdade.

17. O contrato concluía-se entre partes no estilo que ainda se observa hoje na regulação comum de certos interêsses patrimoniais de menor significação social ou importância econômica. A complexidade da vida econômica, na atualidade, determinou, porém, a modificação dêsse estilo, introduzindo, em largos e importantes setôres da atividade econômica, o chamado contrato em massa, a produção em série na fábrica das relações jurídicas.

Os contratos seriados realizam-se, hoje, às carradas, nos transportes, nos seguros, nas operações bancárias e nas relações de trabalho. Pela sua quantidade, modificaram a qualidade, estourando as comportas de sua conceituação clássica.

Uma das mais interessantes conseqüências dêsse nôvo processo de vinculação jurídica das pessoas foi a substituição da regulamentação individual do conteúdo da relação contratual, assim criada, por um regulamento coletivo, coativo e inalterável. Novas necessidades do comércio jurídico impuseram a pré-ordenação uniforme de quase tôdas as cláusulas do negócio jurídico em série, criando figuras jurídicas irredutíveis ao esquema clássico do contrato, que confirmam a estreiteza do seu conceito, formulado em outro período histórico.

Os contratos de adesão tornaram-se moeda corrente na vida moderna, segundo a feliz expressão de HENRI DE PAGE. Quem os examine atentamente, choca-se com a deformação que os torna irreco- 
nhecíveis à luz da conceituação tradicional do contrato. Em certos setôres, não é sòmente uma das partes que tem de curvar-se à vontade da outra, senão também esta há de conformar sua liberdade de contratar à vontade do Estado, de sorte que ocorre dupla adesão, mais não servindo o contrato do que de agente catalisador de relações jurídicas pre-ordenadas.

Noutras situações, finge a lei que as partes celebraram contrato, mas, verdadeiramente, são obrigadas a constituir o vínculo jurídico, dando-se-lhe o tratamento dispensado às relações contratuais devido à conveniência de assimilar as duas técnicas. Salta aos olhos, porém, que o contrato impôsto ou forçado refoge inteiramente à armadura contratual, como, de resto, a situação em que, por exemplo, alguém se encontra de ter sido segurado sem sequer saber que o foi.

Nem ao conceito se pode ajustar o contrato necessário, a cuja conclusão se acham adstritas emprêsas que devem permanecer em constante oferta de contratar, não podendo recusar a qualquer interessado a prestação dos serviços de que se encarregam.

Do modêlo clássico também se distanciam o contrato-tipo, o contrato regulamentado, o contrato autorizado, e o contrato coletivo.

18. Separam-se hoje, do negócio jurídico os atos não-negociais, que dantes eram confundidos. Incluíam-se naquela categoria os atos materiais, em que a correspondente manifestação da vontade subsiste de per si, e as participações, nas quais precisa ser dirigida a determinada pessoa (cf. FADDA e BENSA, notas a WINDSCHEID), mas hoje se reconhece que são figuras distintas, com substantividade própria e disciplina diferente.

19. Urge assim reformular os conceitos a fim de ordenar, em têrmos congruentes, as expressões jurídicas da cultura dos novos tempos, aproximando a realidade jurídica da realidade social, mediante esfôrço dogmático que alcance o nível das grandes construções teóricas.

Mas a despeito dos esforços dos mais lúcidos cultores da ciência jurídica para atualizá-la, sintonizando-a com as novas exigências sociais e velhas aspirações humanas inatendidas, conserva-se o Direito dominado, na política que o orienta e na técnica que o expressa, pela filosofia que o marcou no século passado.

Tal é a filosofia do nosso Código Civil. Tal é sua técnica. Continuo a pensar que está a carecer, por isso, de uma reforma que se não contente com simples retoque da legislação híbrida que expressa - Direito Privado Brasileiro nos dias correntes. 
O grande número de leis especiais, que contradizem os princípios do Código, comprova que êsses princípios são contestáveis e que não mais correspondem às necessidades de nossa época.

20. Entretanto, foi, em seu tempo, um Código progressista. Chegou mesmo a avançar o sinal, ao desprezar a própria realidade histórica para cair, aqui e acolá, num utopismo entusiástico.

Durante tôda a sua longa gestação, os elaboradores, tiveram as vistas dirigidas para o futuro, e, em seguida à sua promulgação, a muitos se afigurou ser um corpo de leis que, por seu avanço, não se adaptaria às condições de vida da maioria da população.

21. No entanto, bem cedo se atrasaria. A tal ponto que não é possível remoçá-lo pela cirurgia estética que, sem dúvida, Ihe suprimiria as rugas, mas não the restituiria o vigor, nem Ihe rejuvenesceria o espírito.

22. Na luta interminável entre a tradição e o progresso, na controvérsia entre SAVIGNY e BENTHAM, a minha posição é clara. Estou com a renovação e acredito na fôrça renovadora do Direito. 